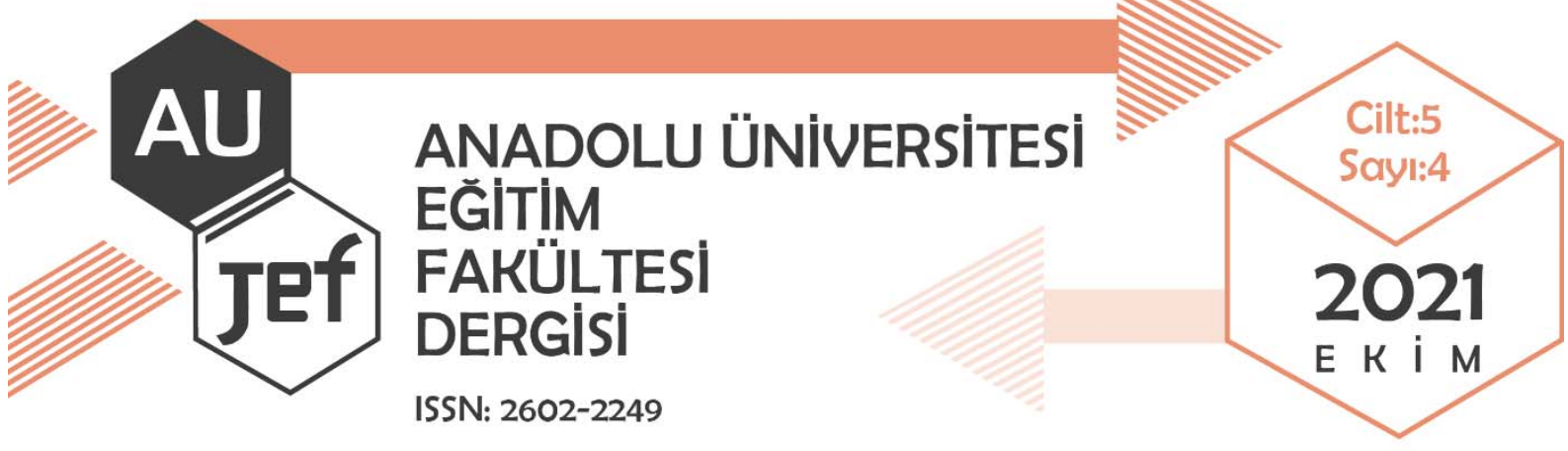

\title{
Ortaokul Sosyal Bilgiler Ders Kitaplarında Küresel İklim Değişikliği Konusunun Yer Alma Durumu
}

\section{The Inclusion of Global Climate Change in Middle School Social Studies Textbooks}

Önder ERYILMAZ ${ }^{1}$

Makale Türü: Araştırma Makalesi

Başvuru Tarihi: 23.04.2021

Kabul Tarihi: 15.09 .2021

Atıf İçin: Eryılmaz, Ö. (2021). Ortaokul sosyal bilgiler ders kitaplarında küresel iklim değişikliği konusunun yer alma durumu. Anadolu Üniversitesi Eğitim Fakültesi Dergisi (AUJEF), 5(4), 385-401.

ÖZ: $\mathrm{Bu}$ araştırmanın temel amacı ortaokul sosyal bilgiler ders kitaplarında Küresel İklim Değişikliği (KID) konusuna nasıl yer verildiğinin incelenmesidir. Araştırma nitel araştırma yöntemlerinden doküman incelemesine göre desenlenmiştir. Araştırmada 2020-2021 eğitim öğretim yılında Millî Eğitim Bakanlığı'na bağlı ortaokullarda kullanılan 5, 6 ve 7. sınıf sosyal bilgiler ders kitapları incelenmiştir. Ortaokul sosyal bilgiler ders kitapları araştırmanın amacı doğrultusunda betimsel analiz yaklaşımı benimsenerek analiz edilmiştir. Araştırmada incelenen ders kitaplarının analizi sonucunda KİD ile ilişkili bilgilere yalnızca 5 ve 7. sınıf sosyal bilgiler ders kitaplarında yer verildiği, 6. sınıf sosyal bilgiler ders kitabında KiD ile ilişkili olarak sunulan bilgilerin bulunmadığı belirlenmiştir. 5. sınıf sosyal bilgiler ders kitabında yalnızca KID'in temel nedeni olan küresel ısınmaya ilişkin yüzeysel bilgilerin verildiği görülmüştür. 7. sınıf sosyal bilgiler ders kitabındaki KID ile ilgili bilgiler incelendiğinde, özellikle KID'in oluşumu, nedenleri ve olası etkilerine ilişkin oldukça sınırlı bilgilere yer verildiği belirlenmiştir. Diğer yandan KID'in yakın gelecekte olası ekonomik, sosyal ve psikolojik etkilerine ilişkin yüzeysel açıklanmadığı sonucuna ulaşılmıştır. Bunların yanında KİD’in gelecekteki olası etkilerini en az indirgemek için alınması gereken önlemlere ilişkin de oldukça sınırlı bilgilere yer verildiği görülmüştür. Araştırmanın sonuçları göz önünde bulundurularak, sosyal bilgiler ders kitaplarına ve sosyal bilgiler dersi ögretim programına yönelik birtakım öneriler sunulmuştur.

Anahtar sözcükler: Küresel iklim değişikliği, Sosyal bilgiler, Sosyal bilgiler ders kitapları

ABSTRACT: The main purpose of this study is to examine how information about Global Climate Change (GCC) are presented in middle school social studies textbooks. Document analysis which is one of the qualitative research methods was employed in the study. $5^{\text {th }} 6^{\text {th }}$ and $7^{\text {th- }}$ grade social studies textbooks that are used in the middle schools in the 2020-2021 academic year were examined. Descriptive analysis was conducted to analyze middle school social studies textbooks. As a result of the analysis, it is revealed that only $5^{\text {th }}$ and $7^{\text {th }}$-grade middle school social studies textbooks include information about GCC, $6^{\text {th }}$-grade middle school social studies textbooks do not include any related information about GCC. Besides, it has been observed that only information about global warming which is the main reason for GCC is presented in $5^{\text {th }}$ grade social studies textbooks. Moreover, it is seen that $7^{\text {th }}$ grade middle school social studies textbooks include limited information about the reasons and expected consequences of GCC. The results show that quite limited information about reasons, occurrence and expected

\footnotetext{
${ }^{1}$ Dr. Öğt. Üyesi, Amasya Üniversitesi, onder.eryilmaz@amasya.edu.tr, ORCID: 0000-0002-4962-889X
} 
negative impacts of GCC are placed in middle school social studies textbooks. Moreover, it has been concluded that no information about economic, psychological and political aspects of results of GCC are not presented in middle school social studies textbooks. In addition, it is revealed that information about preventing expected negative impacts of GCC are too limited in textbooks. At the end of the study, some recommendations are presented based on the results of the research.

Keywords: Global climate change, social studies, social studies textbooks. 


\section{GíRiş}

Küresel İklim Değişikliği (KİD), günümüzde insanoğlunun yüzleştiği ve yakın gelecekte de yüzleşmeye devam edeceği en büyük tehdit olarak değerlendirilmektedir (Clayton vd., 2015; Li ve Liu, 2021). KİD yalnızca insanların değil aynı zamanda diğer tüm canlıların yaşamlarını tehdit etmekdir (Wang ve $\mathrm{Gu}, 2021$ ). Bundan dolayı bilim çevrelerinin gündemindeki en önemli konular arasında yer almaktadır (McMichael ve Haines, 1997).

Bilim insanlarına göre dünyanın oluşumundan günümüze kadar olan süreç içerisinde farklı zamanlarda KIDD meydana gelmiştir. Ancak günümüzde yaşanan KİD ve olası olumsuz etkilerinin en temel sebebinin diğerlerinden farklı olarak antropojenik olduğu açıklanmaktadır. Başka bir ifadeyle günümüzde etkilerini gözlemlemeye başladığımız KİD'in en temel nedeni insan eliyle gerçekleştirilmiş olan faaliyetlerdir (Boon, 2016; Öztürk, 2002). Bu faaliyetlerin başında yoğun fosil yakıt kullanımı, ormanlık alanların bilinçsizce kullanımı ve azalması, sanayileşmenin artması gelmektedir. Tüm bu faaliyetler sonucunda atmosfere oldukça fazla salınan karbon dioksit, nitrojen dioksit, sülfür dioksit ve metan gibi zararlı gazlar sera etkisi yaratmakta ve bu gazların bir kısmı atmosferde tutulduğu için dünyanın ortalama sıcaklığını artmaktadır (MacCracken, 2008; Nema, Nema ve Roy, 2012). Başka bir deyişle bu faaliyetler küresel isınmaya neden olmakta, küresel ısınma sonucunda KİD meydana gelmektedir.

KİD'in doğal yaşam üzerindeki etkileri 20. yüzyılın son yıllarından itibaren artarak hissedilmeye başlanmıştır. Kutup bölgelerindeki kalıcı kar sınırları daralmaya, buz kalınlıkları incelmeye, dünyanın çeşitli bölgelerindeki içilebilir su kaynakları niceliksel ve niteliksel olarak azalmaya, faunalarda ve floralarda değişimler yaşanmaya, birçok canlı türünün nesli tehlike altında olmaya, tarım ürünlerinin yetişme sürelerinde ve kalitelerinde olumsuz değişimler gözlemlenmeye başlanmıştır. Bunların yanında bazı bölgelerde hiç görülmeyen ekstrem hava olayları görülmeye başlanmış, orman yangınları artmış ve deniz seviyesinde yükselmeler meydana gelmiştir. Doğal afet boyutunda gerçekleşen bu olaylar insanların yaşam alanları etkilemeye başlamıştır (Hükümetlerarası İklim Değişikliği Paneli (IPCC), 2014). Yakın gelecekte ise KİD’in doğal yaşam üzerinde yol açtığı ekolojik sorunlardan dolayı tarımsal üretim dengesinde bozulma, ulaşım hizmetlerindeki aksaklıklar gibi ekonomik; umutsuzluk, depresyon, kayg1 bozuklukları, stres, aidiyet yoksunluğu, madde bağımlılı̆̆ gibi psikolojik ve göç, sınıfsal mücadeleler, işsizlik, su savaşları gibi toplumsal sorunların yaşanacağı ön görülmektedir (Brady, 2020; Clayton, 2015). Bunların yanında artan sıcaklıklara bağlı olarak bazı enfeksiyon hastalıklarının daha sık görüleceği düşünülmektedir (McMichael ve Haines, 1997). KİD'in yol açacağı sorunlardan en çok etkilenecek kişiler ise gelişmemiş ve gelişmekte olan ülkelerde yaşayan günümüzün çocukları ve gençleri olacaktır (Bongay ve Blum, 2010; Birleşmiş Milletler Çocuklara Yardım Fornu (UNICEF), 2009;).

KİD'in gelecekte görülmesi olası olumsuz etkilerine yönelik olarak birçok kurum ve kuruluş kararlar alıp politika geliştirmiş; sayısız araştırmacılar ve araştırma merkezleri çeşitli ölçeklerde araştırmalar yapıp sonuçlarını paylaşmıştır (Meehan, Levy ve Collet-Gildard, 2016; Siegner ve Stapert, 2020). Gerçekleştirilen araştırmalar ve tartışmalar KİD'in gelecekteki olası etkilerini azaltmak için iki etkili çözüm yolu önermektedir. Bunlardan birisi KİD’i tetikleyen sera gazı salınımlarının azaltılmasıdır. Ancak sera gazı salınımının azaltılması, olası etkileri azaltsa da mevcut KID'in etkilerini belli bir zamana kadar deneyimleyecek olmamızın önüne geçemeyecektir. Bunun için daha etkili bir yol olan adaptasyon önerilmektedir. Araştırmalar, insanoğlunun KİD'in kaçınılmaz sonuçları ile mutlaka yüzleşeceğini, dolayısıyla tüm alt yapı, ekonomik ve sosyolojik sistemlerini KİD'e adapte etmesi gerektiğini önermektedir. Tüm bu yaklaşımların uygulanabilmesi için en etkili yol ise eğitim olarak görülmektedir 
(Anderson, 2012; Stevenson, Nicholls ve Whitehouse, 2017). Eğitim KİD'in antropojenik nedenlerini en aza indirgemek ve insanoğlunun yeni iklim koşullarına uyum sağlaması için en etkili yollardan biridir (Boakye, 2015; Feinstein ve Mach, 2020). Bunun için birçok ülke eğitim politikalarında ve programlarında KiD’e ve gelecekteki olası etkilerine yer vermiştir (Chang ve Pascua, 2017).

KİD'in özellikle gelecekteki olası sosyal ve ekonomik etkilerine ilişkin farkındalık kazandırılmasını sağlayacak ve bu doğrultuda davranış değişikliği meydana getirebilecek en uygun derslerden birinin sosyal bilgiler dersi olduğu söylenebilir (Harris vd., 2016; Kissling ve Bell, 2020; Kumler ve Vosburg-Bluem, 2014). Çünkü disiplinler arası bir yapıya sahip olan sosyal bilgiler dersi öğrencilere toplumsal yaşam içerisinde aktif rol almalarını sağlayacak bilgi, beceri ve değer kazandırarak onların yaşanan toplumsal sorunlara ilişkin farkındalık ve bu sorunların çözümüne yönelik davranış geliştirmelerine yardımcı olmaktadır (Öztürk, 2012; Sosyal Bilgiler Dersi Öğretim Programı (SBDÖP), 2018)

Ülkemizde ilkokul 4 ve ortaokul 5, 6 ve 7. sınıflarda okutulan sosyal bilgiler dersi KİD ile ilgili konuları içermektedir (Özdem vd., 2014) SBDÖP'nin özel amaçları incelendiğinde öğrencilere doğal çevreye duyarlılık, kaynakların sınırlılığına ilişkin farkındalık, çevrenin korunması, sürdürülebilir yaşam, toplumsal sorunlar, sosyal katılım gibi bilişsel ve duyuşsal özelliklerin kazandırılmasının amaçlandığı görülmektedir. Ayrıca 7. sınıf küresel bağlantılar öğrenme alanındaki dördüncü kazanım olan "Arkadaşlarılla birlikte küresel sorunların çözümüne yönelik fikir önerileri geliştirir (KIDD, doğal afetler, açlık, terör ve göç konuları ele alınacaktır)" kazanımının doğrudan KİD ile ilgili olduğu görülmektedir (SBDÖP, 2018). Tüm bu bilgiler göz önünde bulundurulduğunda sosyal bilgiler dersinde öğrencilere KİD'e yönelik bilişsel ve duyuşsal farkındalıkların kazandırılması beklenmektedir. Bu bağlamda sosyal bilgiler öğretmenlerinin derslerinde başvurdukları en önemli kaynaklardan birisi olan sosyal bilgiler ders kitaplarında da KID’e ilişkin bilgilerin verilmesi gerekmektedir.

Alan yazın incelendiğinde sosyal bilgiler öğretmenlerinin KID'in yer aldığı ekolojik sorunlara ilişkin inançları ve uygulamaları (Chandler ve Marri, 2012; Kissling ve Bell, 2020), KID ile ilgili düzenlenen eğitimin sosyal bilgiler öğretmenlerinin KİD’e yönelik farkındalıklarına etkisi (Dal vd., 2015), sosyal bilgiler öğretmen adaylarının KID’e ilişkin bilgi sahibi oldukları medya araçlarının güvenirliği ile ilgili farkındalıkları (Damico ve Panos, 2018), sosyal bilgiler ve fen bilimleri öğretmen adaylarının atmosferik çevresel problemlere ilişkin düzeylerinin karşılaştırılması (Ürey vd., 2020), Türkiye, Kanada ve Hong Kong SBDÖP'deki Kİ'in incelenmesi (Özkaral, 2019) ile ilgili araştırmaların olduğu görülmüştür. Ayrıca ABD'de ortaöğretim sosyal bilgiler ders kitaplarında ve Nijerya'daki ortaokul SBDÖP'de KİD'e ilişkin bilgilere nasıl yer verildiği ile ilgili araştırmanın var olduğu tespit edilmiştir (Meehan, Levy ve Collet-Gildard, 2016; Njoku, 2016). Bunların yanında sosyal bilgiler ile küresel ısınmanın ilişkilendirilerek gerçekleştirildiği araştırmaların var olduğu görülmüştür. $\mathrm{Bu}$ araştırmaların sosyal bilgiler öğretmen adaylarının küresel ısınma kavramına yönelik metaforik algıları (Kaya, 2013), zihinsel modelleri (Karakuş ve Yel, 2019) ve görüşleri (Aksan ve Çelikler, 2013), karikatürler ile küresel 1sınma eğitiminin etkililiği (Tuncel, 2017), ABD'deki sosyal bilgiler ders kitaplarında ve öğretim programlarında küresel ısınma (Meehan, 2012) ile ilgili olduğu görülmüştür. Ancak Türkiye'de sosyal bilgiler ders kitaplarındaki KİD ile ilgili oldukça sınırlı sayıda araştırmanın olduğu belirlenmiş̧tir. Demir (2018) tarafından gerçekleştirilen araştırmada SBDÖP'de ve sosyal bilgiler ders kitaplarında KİD ile ilgili bilgiler incelenmiştir. Ancak araştırmada incelenen ders kitaplarının farklı yayınevlerine ait olduğu tespit edilmiştir. Ayrıca elde edilen bulguların birçoğunun iklim ile ilgili olduğu ve bu bilgilerin KİD ile ilişkilendirilerek sunulmadığı görülmüştür. Dolayısıyla elde edilen bu sonuçlar, sosyal bilgiler ders kitaplarında KID'e yer verilme durumuna ilişkin hatalı çıkarımlara neden 
olabileceğini düşündürmektedir. KİD'in sosyal bilgiler dersi için öneminden ve alan yazındaki mevcut durumdan hareketle bu araştırmada ortaokul sosyal bilgiler ders kitaplarında KIDD konusunun yer alma durumunun incelenmesi amaçlanmıştır.

\section{YÖNTEM}

Bu bölümde araştırmanın yöntemine ilişkin bilgiler verilmiştir. Bu kapsamda araştırmanın deseni, araştırma kapsamında incelenen dokümanlar ve verilerin analizine ilişkin bilgiler açıklanmıştır.

\subsection{Araştırmanın Deseni}

Ortaokul sosyal bilgiler ders kitaplarındaki KID ile ilgili bilgilere nasıl yer verildiğinin incelendiği bu araştırma, nitel araştırma yöntemlerinden doküman incelemesine göre desenlenmiştir. Eğitim araştırmalarında doküman incelemesi destekleyici bir yöntem olarak kullanıldığı gibi, araştırmanın merkezine alınmış bir yöntem olarak da kullanılmaktadır (Ulutaş, 2015). Bu araştırmada doküman incelemesi araştırmanın merkezine alınarak kullanılmış, araştırma doküman incelemesine göre gerçekleştirilmiştir.

\subsection{Dokümanlar}

Araştırma kapsamında 5, 6 ve 7. sınıf sosyal bilgiler ders kitapları incelenmiştir. Araştırmada incelenen sosyal bilgiler ders kitaplarına ilişkin bilgiler Tablo 1'de gösterilmiştir.

Tablo 1: Sosyal Bilgiler Ders Kitaplarına İlişkin Bilgiler

\begin{tabular}{cccc}
\hline Sınıf Düzeyi & Yayın Evi & Basım Yılı & Sayfa Sayısı \\
\hline 5. Sınıf & Ata Yayıncılık & 2020 & 192 \\
6. Sınıf & Anadolu Yayıncılık & 2020 & 288 \\
7. Sınıf & Eğitim Yayıncılık & 2020 & 252 \\
\hline
\end{tabular}

Tablo 1'de görüldüğü üzere araştırma kapsamında incelenen 5. sinıf sosyal bilgiler ders kitab1 2020 yılında Ata Yayıncılık tarafından basılmış olup, 192 sayfadan oluşmaktadır. 6. sınıf sosyal bilgiler ders kitabı ise 2020 yılında Anadolu Yayıncılık tarafından basılmış olup, 288 sayfadan oluşmaktadır. 7. sınıf sosyal bilgiler ders kitabı ise 2020 yılında Eğitim Yayıncılık tarafından basılmış olup 252 sayfadan oluşmaktadır. Araştırmacının talebi doğrultusunda ilgili Milli Eğitim Müdürlüğü yalnızca Tablo 1'de belirtilen kitapları temin ettiği için araştırmada yalnızca bu kitaplar analiz edilmişsir. Bu durum aynı zamanda araştırmanın sınırlılığını oluşturmaktadır.

\subsection{Verilerin Analizi}

Ortaokul sosyal bilgiler ders kitaplarının analiz edildiği bu araştırmada betimsel analiz yaklaşımı benimsenmiştir. Betimsel analiz yaklaşımında elde edilen veriler belirli bir kavramsal çerçeve ile ilişkili olan konu ve temalar kullanılarak gerçekleştirilerek mevcut duruma ilişkin betimleme yapılmaya çalışılır 
(Çırak Kurt, 2019; Yıldırım ve Şimşek, 2013). Bu araştırmada ortaokul ders kitaplarında KİD konusuna yer verilme durumu incelendiği için elde edilen veriler betimsel analiz yaklaşımıyla analiz edilmiştir.

Araştırmanın inandırıcıllğı için uzman görüşü ve akran çözümlemesi stratejilerine başvurulmuştur. Nitel araştırmalarda inandırıcılık araştırma sürecinin, araştırmanın amacı doğrultusunda bilimsel, tutarlı ve doğru biçimde tamamlanması için gerçekleştirilen uygulamaları içermektedir (Krefting, 1990; Lincoln ve Guba, 1985). İnandırıcılık stratejileri arasında olan uzman değerlendirmesi kapsamında araştırmanın amacı, elde edilen dokümanlar ve verilerin analizi sosyal bilgiler eğitimi alanında uzman bir akademisyen ile nitel araştırma yöntemlerine ilişkin deneyim sahibi olan bir akademisyen ile tartışılmıştır. Akran çözümlemesi stratejisi kapsamında ise elde edilen dokümanların bir kısmı bağımsız bir araştırmacıya verilmiş, bağımsız araştırmacı araştırmanın amaçları doğrultusunda elde edilen dokümanları analiz etmiş, bağımsız araştırmacının gerçekleştirmiş olduğu analiz ile araştırmacı tarafından gerçekleştirilen analizler karşılaştırılarak tartışılımış ve araştırmacı bu tartışmalar ışığında verilerin analizi ile elde ettiği bulguları tekrar gözden geçirerek değerlendirmiştir.

\section{BULGULAR}

Bu bölümde araştırma kapsamında elde edilen verilerin analizi sonucun ulaşılan bulgulara yer verilmiştir. Bu doğrultuda öncelikle 5. Sınıf, ardından 7. Sınıf sosyal bilgiler ders kitabındaki KİD ile ilgili bilgilerin nasıl verildiğine ilişkin bulgular sunulmuştur. 6. sınıf sosyal bilgiler ders kitabında KID ile ilgili bulguya ulaşılmadığı için sunulmamıştır.

\subsection{Sınıf Sosyal Bilgiler Ders Kitabında KỉD}

5. sınıf sosyal bilgiler ders kitabı incelendiğinde KID ile ilgili oldukça sınırlı bilgilere yer verildiği görülmüştür. Bu kitapta yalnızca KİD'in temel sebebi olan küresel ısınmaya ilişkin bilgilere yer verilmiştir. Küresel ısınmaya ilişkin bilgilerin İnsanlar, Yerler ve Çevreler Öğrenme alanı altında sunulduğu belirlenmiştir. 5. sınıf sosyal bilgiler ders kitabında yer verilen küresel isınmaya ilişkin bilgiler Görsel 1'de gösterilmiştir.

Farklı gazların bileşiminden oluşan atmosfer, dünyayı yaşanabilir bir gezegen hâline getirmiştir. Ulaşım araçları, fabrika ve konutlardan çıkan zararlı gazlar, sanayi faaliyetleri hava kirliliğine neden olmuştur. Bu değişim beraberinde küresel ısınmayı getirmiştir.

Görsel 1: Küresel Isınmaya İlişskin Bilgiler (5. Sinıf Sosyal Bilgiler Ders Kitabı, 2020, s. 80).

Görsel 1 incelendiğinde küresel ısınma ile ilgili bilgilerin oldukça sınırlı olduğu görülmektedir. $\mathrm{Bu}$ bilgilerin yalnızca küresel ısınmanın oluşmasının nedeni ile ilgili olduğu görülmektedir. Küresel ısınmanın nedenlerine ilişkin daha detaylı bilgilere, küresel ısınma ile ilgili herhangi bir görsele ve küresel ısınmanın etkilerine ilişkin bilgilere yer verilmediği belirlenmiştir. Ayrıca sunulan bilgilerin görseller ile desteklenmediği görülmüştür. 


\subsection{Sınıf Sosyal Bilgiler Ders Kitabında KİD}

7. sınıf sosyal bilgiler ders kitabı incelendiğinde Ülkemizde Nüfus ünitesinin "Nedenleriyle ve Sonuçlarıyla Göç" başlığı altında KİD ile ilgili bilgilere yer verildiği görülmüştür. Bu bilgiler Görsel 2'de gösterilmiştir.

Nüfus değişimindeki önemli unsurlardan biri olan göç, bir kişinin devamlı ikametgâhını esaslı bir süre için değiştirmeyi ifade eden bir nüfus hareketidir. Göç, insanlık tarihi kadar eskidir. Milattan önceki göçler daha çok iklim değişimleri sonucu meydana gelmiştir. İnsanlar en iyi yaşayabilecekleri iklimi olan yerlere göç etmişlerdir. Daha sonraki dönemlerde verimli toprakların, deniz ve su kenarlarının, zengin ham madde kaynaklarının bulunduğu bölgeler göç alan yerlerden olmuştur.

Göç, dış gö̧̧ ve iç göçler olmak üzere ikiye ayrılmaktadır. Dış göç, ülkeler arasında gerçekleşen göçlerdir. İç göçler ise bir ülkede yaşayan insanların bir yerden diğer yere çalışmak, daha iyi hayat şartlarına sahip olmak için yaptıkları göçlerdir. Bu göçler kırdan kente, kırdan kıra, kentten kente, kentten kıra olmaktadır.

İbrahim Atalay, Genel Beşeri ve Ekonomik Coğrafya, s.27-32 (Dïzenlenmistir.)

Görsel 2: Nedenleriyle ve Sonuçlarıyla Göç Başlığı Altındaki KiD ile ilgili Bilgiler (7. Sınıf Sosyal Bilgiler Ders Kitabı, 2020, S. 114)

Görsel 2'de görüldüğü üzere bu bölümde insanların göç etme nedenlerinden birinin KİD olduğu belirtilmiştir. Başka bir ifadeyle KİD'in insan yaşamı üzerindeki etkilerinden bir tanesinin göç olduğu belirtilmiştir. Ancak verilen bu bilginin KİD'in sonuçlarını açıklamak için değil göçün nedenlerini açıklamak için verildiği anlaşılmaktadır.

7. sınıf sosyal bilgiler ders kitabında KİD ile ilişkili bazı bilgilerin "Ekonomi ve Sosyal Hayat" ünitesi kapsamında sunulduğu belirlenmiştir. Bu ünitedeki "Sosyal Hayatta Vakıfların Yeri” başlıklı konu kapsamında KID ile ilgili bilgilere rastlanılmıştır. Bu bilgiler Görsel 3'te gösterilmiştir.

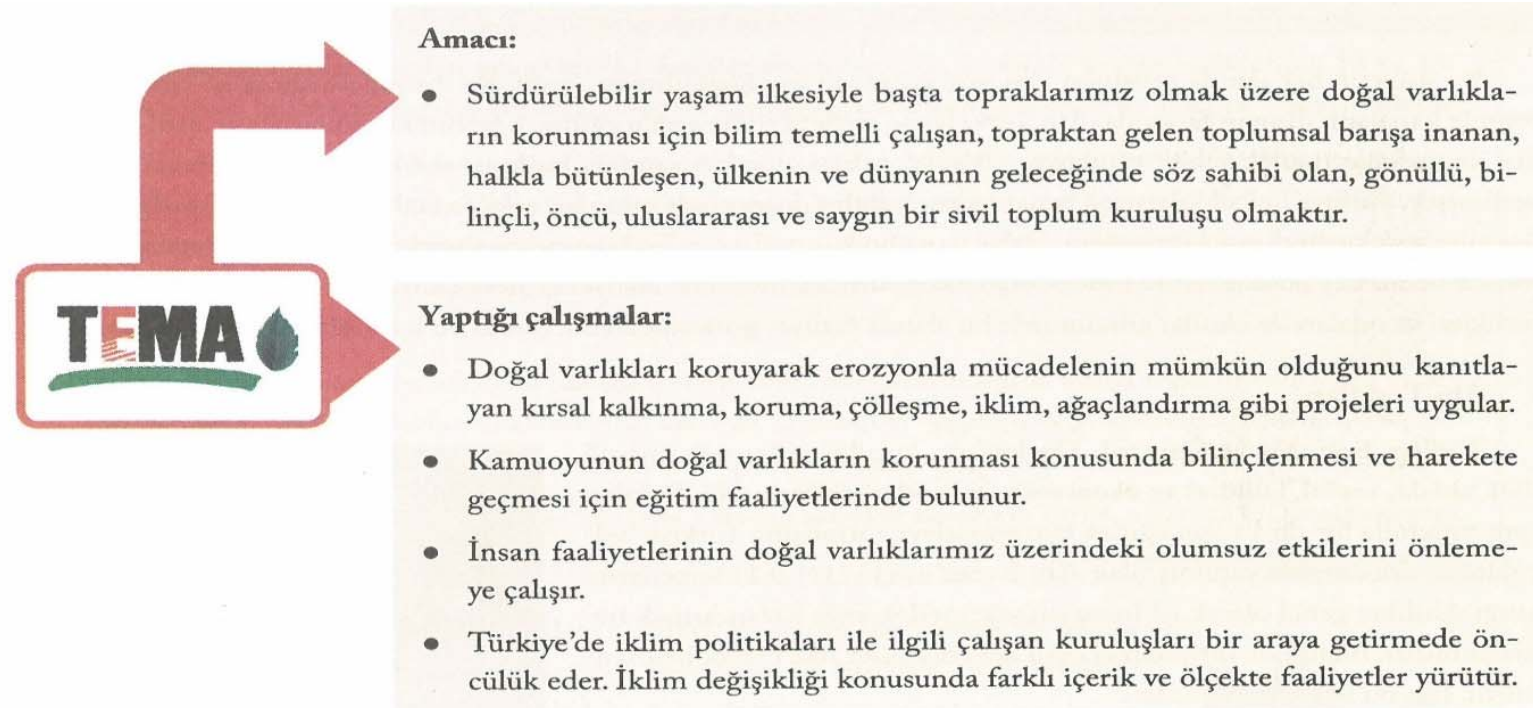

Görsel 3: Tema Vakfi ile İlgili Bilgiler (7. Sını Sosyal Bilgiler Ders Kitabı, s. 165) 
Görsel 3'te görüldüğü üzere TEMA Vakfı'na ilişkin bilgiler verilmiş ve TEMA Vakfı'nın faaliyetlerinden birisinin de KİD konusunda çalışmalar yapmak olduğu açıklanmıştır. Ayrıca TEMA'nın sürdürülebilir yaşam ilkesini benimsediği ifade edilmiştir. Başka bir deyişle ülkemizde KIDD ile ilgili faaliyet gösteren STK' lara ilişkin bilgilere yer verildiği bulgusuna ulaşılmıştır.

"Ekonomi ve Sosyal Hayat" ünitesinde KİD ile ilişkili farklı bilgiler "Yeni Meslekler" konu başlı̆ğ altında da sunulmuştur. Bu bilgiler Görsel 4’te gösterilmiştir.

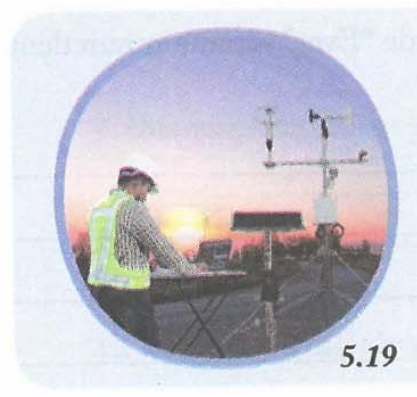

\section{İklim Mühendisi}

İklim değişikliği ve küresel ısınma gibi konular ve ekosistemin bozulmasının insanlık için büyük sorunlar oluşturacağı fikri her geçen gün artıyor. Bu alanda yapılan çalışmalar yoğunlaşıyor. Ülkeler, iş insanları ve girişimciler bu konunun üzerinde çalışıyorlar. Yakın gelecekte bu sorunun derinleşeceğini ve bu alanda çalışıp çözümler üretecek profesyonellere ihtiyacın artacağını öngörmek hiç zor değil.

Genel ă̆ haberi, 2 Mayıs 2018 (Düzenlenmiştir.)

Görsel 4: İklim Mühendisliği Mesleği ile İlgili Bilgiler (7. Sinıf Sosyal Bilgiler Ders Kitabı, s. 171)

Görsel 4'te görüldüğü üzere geleceğin meslekleri arasında gösterilen İklim Mühendisliği'ne ilişkin bilgiler verilirken KİD’e ilişkin bilgiler açıklanmıştır. Bu bilgilerin KİD’in önemi ve gelecekteki olası etkilerine ilişkin olduğu görülmektedir. Sunulan bu bilgiler ile KİD'in yakın gelecekte insanlığ 1 bekleyen en önemli sorunlardan biri olduğuna ve İklim Mühendisliği’nin önemli bir meslek olacağına vurgu yapılmıştır.

KİD ile doğrudan ilgili en fazla bilgi 7. sınıf sosyal bilgiler ders kitabının Ülkeler Arası Köprüler Ünitesi'nin Dünyayı Biz Kurtaracağız başlıklı konusu kapsamında verilmiştir. Konunun başında ilk olarak KID'in bazı küresel problemler ile ilişkili olduğu açıklanmıştır. Bu bilgiler Görsel 5'te gösterilmiştir.

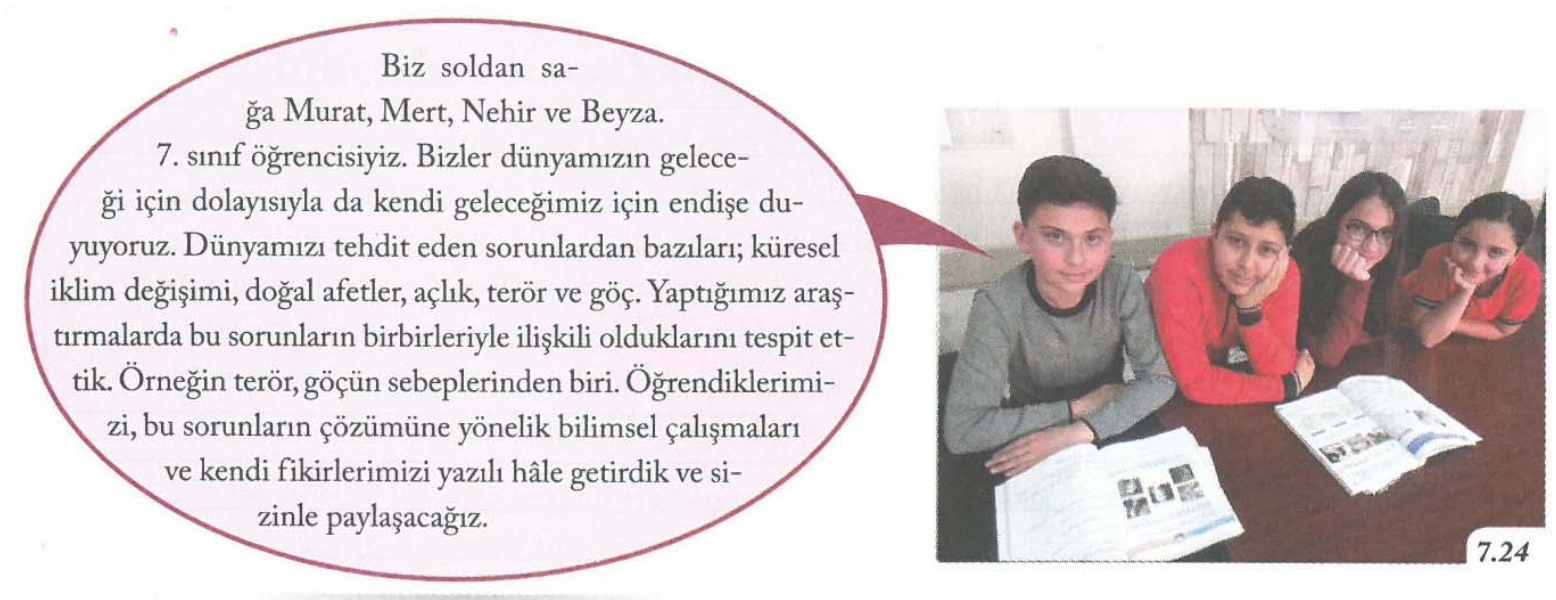

Görsel 5: KID’’in Bazı Küresel Problemler ile İlişkili Olduğunun Açıklandı̆̆ı Görsel (7. Sınıf Sosyal Bilgiler Ders Kitabl, s. 218). 
Görsel 5'te görüldüğü üzere KİD'in dünyamızı tehdit eden sorunlardan biri olduğuna dikkat çekilmiştir. Ayrıca KİD, doğal afetler, açlık, terör ve göç gibi sorunların birbiri ile ilişkili olduğu açıklanmıştır. Başka bir deyişle KİD'in doğal yaşam ve insanların yaşamları üzerindeki bazı etkileri belirtilmiştir.

Dünyayı Biz Kurtaracağız konusu kapsamında KİD ile ilgili en ayrıntılı bilgiye 7. sınıf sosyal bilgiler ders kitabının 219. sayfasında yer verildiği belirlenmiştir. Bu bilgiler Görsel 6'da sunulmuştur.

\section{Küresel İklim Değişikliği}

Sera gibi çalışan atmosfer, sera gazı olarak da nitelendirilen karbondioksit, metan, su buharı, ozon, azot oksit vb. gazlar sayesinde yeryüzünden yansıyan güneş ş̧ılarının bir kısmını tekrar yeryüzüne gönderir. Bir battaniye işlevi gören sera gazları sayesinde yeryüzündeki ortalama sıcaklık, insanların, hayvanların ve bitkilerin hayatını sürdürmesine uygun ısı düzeyini, 15 dereceyi yakalar. Sera gazları olmasaydı yeryüzünün ortalama sıcaklığı $-18^{\circ} \mathrm{C}$ civarında olurdu. Bu da yaşamaya pek elverişli bir $1 s ı$ olmasa gerek. Kuraklık, seller, şiddetli kasırgalar gibi hava olaylarının sıklığı ve etkisinde artış, okyanus ve deniz suyu seviyelerinde yükselme, okyanusların asit oranlarında artış ve buzulların erimesi sonucunda bitkiler, hayvanlar ve insanlar ciddi risk altında kalır.

Bilim dünyası, iklim değişikliğinin yıkıcı etkilerini azaltmak için ortalama sıcaklıklardaki artışın $2^{\circ} \mathrm{C}$ ile sınırlanması gerektiğini ancak mevcut uygulamalarla bu artışın devam edeceğini öngörüyor. Karbondioksit salınımı şu andaki artış hızıyla devam ederse 2060 yılında ortalama sıcaklıklardaki artışın $4^{\circ} \mathrm{C}$ 'yi bulacağını, bu etkilerin özellikle yoksul kesimlerce hissedileceğini belirtiyor. Gerek ekonomik gerekse çevreyle ilgili alınacak ilk önlem enerji talebini

yönetmek. Karbon salınımını azaltmanın en çabuk ve masrafsız yolu enerji verimliliğine yönelik önlemleri almaktan geçiyor. Orman kaybını durdurmak ve tersine hareket ettirmek, bütün olumlu iklim enerji senaryolarının başlıca unsurlarından biridir.

Görsel 6: Küresel İklim Değişikliğine İlişskin Bilgiler (7. Sinıf Sosyal Bilgiler Ders Kitabl, s. 219).

Görsel 6'da görüldüğü gibi KİD ile en çok bilgi bu bölümde verilmiştir. Öncelikle KİD'in nedenleri açıklanmış, sonrasında ise KID'in olası olumsuz etkilerini en aza indirgemek ya da önüne geçmek için yapılması gerekenlere ilişkin genel bilgiler verilmiştir. Bu bilgilerden sonra ise KİD'in etkilerinin neler olabileceğine ilişkin açık uçlu soruya yer verilmiştir. Ancak KİD'in oluşumuna neden olan küresel ısınmayı etkileyen aşırı egzoz gazı salınımı, fabrika bacalarından atmosfere salınan zararlı gazlar, bilinçsiz tüketim, ormanlık alanların azalması gibi insan faaliyetlerine ilişkin bilgilere yer verilmediği görülmektedir. Ayrıca görsel unsur olarak yalnızca bir resim kullanıldı̆̆g, kullanılan resimin boyut ve etki bakımından oldukça yalın olduğu söylenebilir.

Dünyayı Biz Kurtaracağız konusu kapsamında KiD’in bir diğer küresel sorun olan açlık ile iliş̧kilendirilerek verildiği belirlenmiştir. Bu bilgiler Görsel 7'de gösterilmiştir. 


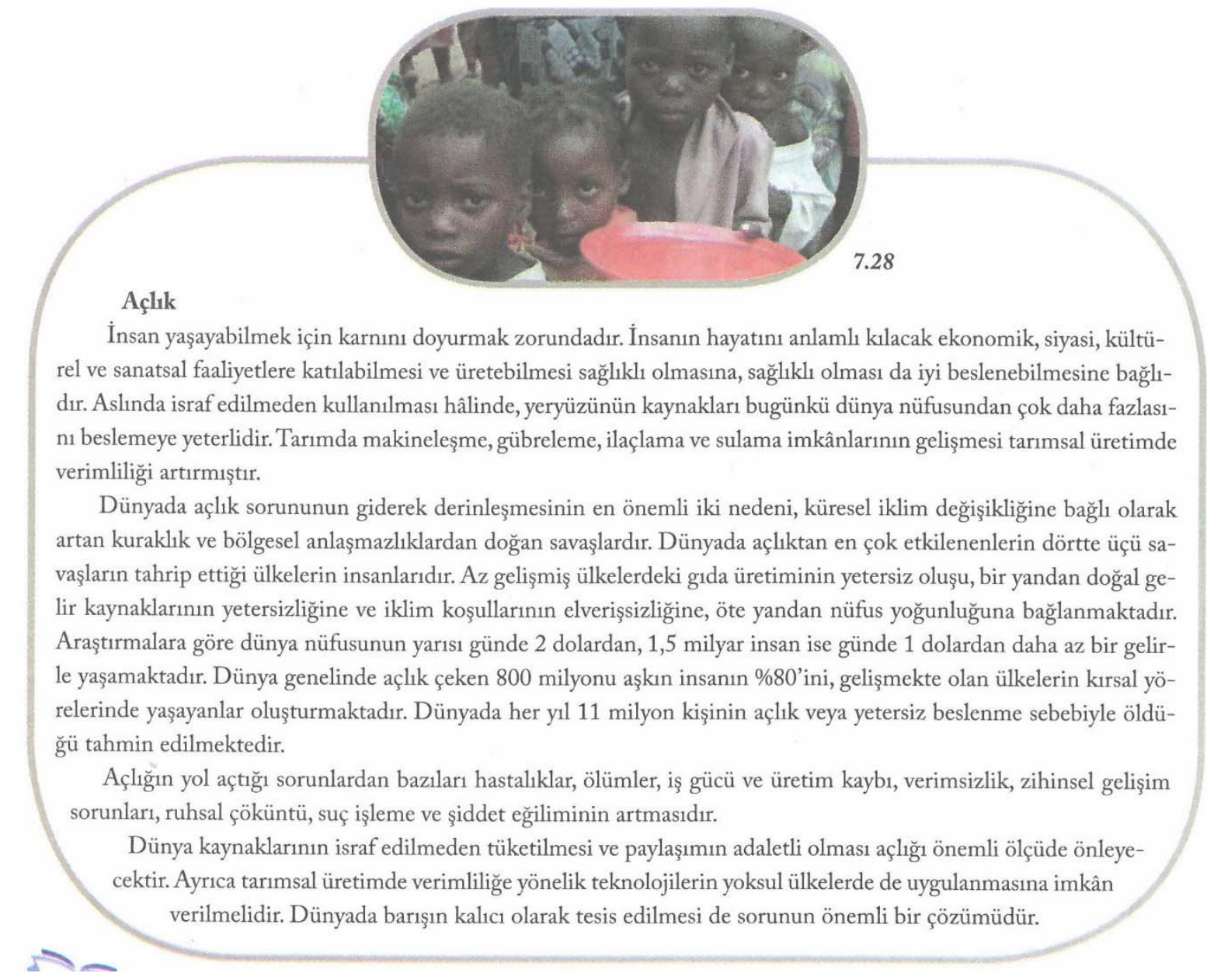

Görsel 7: KID'in Açlık Sorunu ile İliş̧kilendirilmesi (7. Sınıf Sosyal Bilgiler Ders Kitabı, s. 220).

Görsel 7'de görüldüğü üzere KİD, açlığın en önemli nedenleri arasında gösterilmiştir. KİD'in yol açtığı kuraklık ve bölgesel anlaşmazlıklardan dolayı çıkan savaşların açlık sorununun en temel nedeni olduğu açıklanmıştır. Ayrıca KID'in açlığa, açlığın da birçok insanın ölümüne ve ruhsal sorunlara yol açtığı ifade edilmiştir.

\section{SONUÇ, TARTIŞMA VE ÖNERILLER}

Araştırmada KID ile ilgili bilgilerin doğrudan ve en yoğun olarak sunulduğu ders kitabının 7. sınıf sosyal bilgiler ders kitabı olduğu sonucuna ulaşılmıştır. 5. sınıf sosyal bilgiler ders kitabında yalnızca KID'in temel nedeni olan küresel ısınmaya ilişkin yüzeysel bilgilere yer verildiği görülmüştür. 6 . sınıf sosyal bilgiler ders kitabında ise KİD ile ilişkilendirilerek verilen herhangi bir bilginin bulunmadığ 1 belirlenmiştir. KID ile ilgili bilgilerin sadece 7. sınıf sosyal bilgiler ders kitabında sunulmasının temel sebebinin SBDÖP'deki KİD ile doğrudan ilgili kazanımın yalnızca 7. sınıf Küresel Bağlantılar Öğrenme Alanı'nda bulunmasının olduğu düşünülmektedir. Demir (2018)' in gerçekleştirdiği araştırmada da 4, 5 ve 6. sınıf sosyal bilgiler ders kitaplarında KIDD ile ilgili bilgilere yer verilmediği, yalnızca 7. sınıf sosyal bilgiler ders kitabında KİD ile ilgili doğrudan bilgilerin sunulduğu sonucuna ulaşılmıştır. Demir (2018) bu araştırmanın sonucundan farklı olarak 6. sınıf sosyal bilgiler ders kitabında da KİD ile ilişkili olabilecek bilgilerin verildiğini belirtmiştir ancak bu bulgular incelendiğinde yer verilen bilgilerin KID ile ilişkilendirilmediği görülmüştür. Bunların yanında Njoku (2016) tarafından gerçekleştirilen 
araştırmada Nijerya'daki, Meehan (2012) tarafından gerçekleştirilen araştırmada da ABD'deki SBDÖP'de KIDD ve temel nedeni olan küresel 1sınma ile ilgili yeterli bilginin verilmediği sonucuna ulaşılmıştır. Araştırmaların bu sonuçları yalnızca ülkemizdeki değil, dünyanın bazı ülkelerindeki SBDÖP ve dolayısıyla sosyal bilgiler ders kitaplarında KID ile ilgili bilgilerin oldukça sınırlı ve yetersiz olduğunu göstermektedir.

Araştırmada KİD'in nedenleri ve oluşumuna ilişkin bilgilerin yüzeysel biçimde sunulduğu görülmüştür. KİD'in yalnızca sera gazlarının fazla salınımından dolayı oluştuğuna yer verilmiş, ancak bilinçsiz tüketicilik ve ormanların bilinçsizce kullanımı ile ilişkilendirilmemiştir. Ayrıca bu bilgilerin çeşitli görseller ile desteklenmediği görülmüştür. Ancak ortaokul sosyal bilgiler dersinin hedef kitlesi olan öğrencilerin gelişim dönemleri göz önünde bulundurulduğunda, KİD gibi soyut kavramlar ve bilgiler içeren konuların etkili öğretimi için mümkün olduğunca uygun görsellerin işe koşulması tavsiye edilmektedir (Akbaba, 2012; Demircioğlu, 2016). Bu bakımdan KİD'in nedenleri ve oluşumuna ilişkin bilgilerin ve görsellerle desteklenmesinin yetersiz olduğu söylenebilir.

Sosyal bilgiler ders kitaplarında KID'in doğrudan etkileri arasında kuraklık, göç, doğal afetler, deniz ve okyanus suyu seviyesindeki artış ve buzulların erimesinin olduğuna yer verilmiş, ancak KİD'in neden olacağı psikolojik, siyasal ve ekonomik sorunlar ile salgın hastalıklara ilişkin bilgilere yer verilmemiştir. Bu sorunların bir kısmı KID'in etkisi ile ortaya çıkacak açlık sorununun olası sonuçları olarak açıklanmıştır. Ayrıca özellikle yakın gelecekte KID'in etkilerinin daha fazla hissedileceğine ilişkin açıklamaların etkili biçimde yapılmadığı belirlenmiştir. Bunların yanında tarihsel süreç içerisinde zaman zaman iklim değişikliklerinin meydana geldiğine, ancak günümüzdeki iklim değişikliğinin diğerlerinden en önemli farkının oluşumunu tetikleyen en büyük faktörün günümüzdeki beşerî faaliyetler olduğuna ilişkin açıklamaların yapılmadığı görülmüştür. Demir (2018) de gerçekleştirdiği araştırmada, araştırmanın bu sonuçları ile örtüşen bulgulara ulaşmıştır. Tüm bu bilgiler göz önünde bulundurulduğunda sosyal bilgiler ders kitaplarında KİD'in günümüzde ve yakın gelecekteki olumsuz etkilerine ilişkin yer verilen bilgilerin oldukça sınırlı olduğu söylenebilir.

Araştırmada KİD'in olası etkilerini en aza indirgemek ya da önlemek için alınabilecek önlemler arasında yenilebilir enerji kaynaklarına yönelmek ve ormanlık alanların arttırılmasını sağlamak olarak gösterilmiştir. Araştırmanın bu sonuçlarına benzer şekilde Meehan (2012) ve Meehan, Levy ve ColletGillar (2017) tarafından gerçekleştirilen araştırmalarda ABD'de uygulanan SBDÖP'nda KİD'in ve küresel ısınmanın olumsuz etkilerini önlemek için açıklanan stratejilerin oldukça sınırlı olduğu sonucuna ulaşılmıştır. Araştırmacılar KİD'in etkilerini en aza indirgemek için etkili bir diğer yolun insan yaşamının yeni iklim şartlarına uyum sağlayacak biçimde düzenlenmesi olduğunu ifade etmektedir (Anderson, 2012; Boakye, 2015; Feinstein ve Mach, 2020; Laukkonen, vd., 2009; Wilbanks ve Sathaye, 2007). Ancak sosyal bilgiler ders kitaplarında KİD sonrasında oluşacak yeni iklim şartlarına uyum ile igili herhangi bir bilgiye yer verilmediği görülmüştür. Bu bilgiler göz önünde bulundurularak sosyal bilgiler ders kitaplarında KID'in olası etkilerine ilişkin çözüm yolları ile ilgili yeterli bilgiye ve açılamalara yer verilmediği söylenebilir.

Sosyal bilgiler ders kitabında KİD ile ilgili değerlendirmelerin yalnızca kelime ilişkilendirme testi kullanılarak yapıldığ 1 görülmüştür. Başka bir ifadeyle çeşitli ölçme ve değerlendirme araçlarının kullanılmadığı görülmüştür. Ayrıca sosyal bilgiler ders kitabında KIDD ile ilgili değerlendirmelerin öğrencilerin üst bilişsel alanlarına yönelik olmadığı belirlenmiştir. 
Araştırmada elde edilen sonuçlardan hareketle aşağıdaki öneriler geliştirilmiştir:

- Ortaokul sosyal bilgiler ders kitaplarında KID ile ilgili bilgilere, SBDÖP'nın sarmal yapısına uygun biçimde her sınıf düzeyinde verilmelidir.

- Ortaokul sosyal bilgiler ders kitaplarında KİD'in doğal yaşam üzerindeki etkilerinin yanı sıra ekonomik, sosyal, siyasal ve psikolojik etkileri göz önünde bulundurulduğunda, bu konular ile ilgili bilgiler ile ilişkilendirilebilir.

- Ortaokul sosyal bilgiler ders kitaplarında KID'in oluşumunun yanı sıra nedenlerinin ve sonuçlarının somutlaştırılması için etkili görsellere yer verilmelidir.

- Ortaokul sosyal bilgiler ders kitaplarında KID, özellikle farklı sınıf düzeylerindeki İnsanlar, Yerler ve Çevreler öğrenme alanında iklim, nüfus, yerleşme ve ekonomik faaliyetler ile ilgili konular ile ilişkilendirilebilir. Bu ilişkilendirmeler çeşitli okuma parçaları, karikatürler ya da gazete haberleri biçiminde gerçekleştirilebilir. 


\section{KAYNAKLAR}

Akbaba, B. (2012). Sosyal bilgiler öğretiminde görsel materyallerin kullanımı. M. Safran (Ed.). Sosyal bilgiler ögretimi içinde (ss. 283-319). Ankara: Pegem Akademi.

Aksan, Z. ve Çelikler, D. (2013). İlköğretim öğretmen adaylarının küresel ısınma konusundaki görüşleri. Eskişehir Osmangazi Üniversitesi Sosyal Bilimler Dergisi, 14(1), 49-67.

Anderson, A. (2012). Climate change education for mitigation and adaptation. Journal of Education for Sustainable Development, 6(2), 191-206.

Boakye, C. (2015). Climate change education: The role of pre-tertiary science curricula in Ghana. Sage Open, 5(4), $1-10$.

Bongay, C. \& Blum, N. (2010). Education responses to climate change and quality: Two parts of the same agenda? International Journal of Educational Development, 30, 359-368

Boon, H. J. (2016). Pre-service teachers and climate change: A stalemate? Australian Journal of Teacher Education, 41(4), 39-63.

Brady, J. M. (2020). Global climate change and human health. Journal of PeriAnesthesia Nursing, 35, 89-90.

Chandler, T. \& Marri, A. R. (2012). Civic engagement about climate change: A case study of three educators and their practises. The Journal of Social Studies Research, 36(1), 47-74.

Chang, C.H. \& Pascua, L. (2017). The curriculum of climate change education: A case for Singapore. The Journal of Enviromental Education, 48(3), 172-181.

Clayton, S., Devine-Wright, P., Stern, P. C., Whitmarsh, L., Carrico, A., Steg, L., Swim, J. \& Bonnes, M. (2015). Psychological research and global climate change. Nature Climate Change, 5, 640-646.

Çırak Kurt, S. (2019). Nitel veri analizi. S. Şen \& İ. Yıldırım (Ed.). Eğitimde araştırma yöntemleri içinde (ss. 439463). Ankara: Nobel Yayıncilık.

Dal, B., Öztürk, N., Alper, U. Sönmez, D. \& Çökelez, A. (2015). An analysis of the teachers' climate change awareness. Athesn Journal of Education, 2(2), 111-122.

Damico, J. S. \& Panos, A. (2018). Civic media literacy as 21 st century source work: Future social studies teachers examine web sources about climate change. The Journal of Social Studies Research, 42, 345-359.

Demir, H. (2018). 2018 sosyal bilgiler öğretim programında ve ders kitaplarında iklim değişikliği (Yayımlanmamış Yüksek Lisans Tezi). Ankara Üniversitesi Eğitim Bilimleri Enstitüsü, Ankara.

Demircioğlu, E. (2016). Sosyal bilgiler öğretimi ve ders kitapları. D. Dilek (Ed.). Sosyal bilgiler öğretimi içinde (ss.577-599). Ankara: Pegem Akademi.

Feinstein, N. W. \& Mach, K. J. (2020). Three roles for education in climate change adaptation. Climate Policy, $20(3), 317-322$.

Harris, C. A., Kharecha, P., Goble, P. \& Goble, R. (2016). The climate is a-changin': Teaching civic competence for a sustainable climate. Social Studies and Young Learner, 28(3), 17-20.

IPCC (2014). Climate Change 2014: Synthesis Report: Contribution of Working Groups I, II and III to the Fifth Assessment Report of the Intergovernmental Panel on Climate Change [Core Writing Team, R.K. Pachauri and L.A. Meyer (eds.)]. IPCC, Geneva, Switzerland, 151 pp.

Karakuş, U. \& Yel, Ü. (2019). The mental models of social studies teacher candidates on global warming. International Journal of Geography and Geography Education (IGGE), 40, 109-123.

Kaya, M. F. (2013). Sosyal bilgiler öğretmen adaylarının "küresel ısınma" kavramına yönelik metafor algıları. Doğu Coğrafya Dergisi, 18(29), 117-134.

Kissling, M. T. \& Bell, J. T. (2020). Teaching social studies amid ecological crisis. Theory \& Research in Social Education, 48(1), 1-31.

Krefting, L. (1990). Rigor in qualitative research: The assessment of trustworthiness. The American Journal of Occupational Therapy, 45(3), 214-222.

Kumler, L. M. \& Vosburg-Bluem, B. (2014). Climate change in the social studies classroom: A "why" and "how to" guide using C3 Framework. Social Education, 78(5), 225-229. 
Laukkonen, J., Blanco, P. K., Lenhart, J., Keiner, M., Cavric, B. \& Kinuthia-Njenga, C. (2009). Combining climate change adaptation and mitigation measures at the local level. Habitat International, 33, 287-292.

Li, Y. \& Liu, S. (2021). Examining Taiwanese students' views on climate change and the teaching of climate change in the context of higher education. Research in Science \& Technological Education, 1-14.

Lincoln, Y. S. \& Guba, E. G. (1985). Naturalistic Inquiry. California: Sage.

MacCracken, M. C. (2008). Prospects for future climate change and the reasons for early action. Journal of the Air \& Waste Management Association, 58(6), 735-786.

McMichael, A. J. \& Haines, A. (1997). Global climate change: potential effects on health. BMJ, 315, 805-809.

Meehan, C. R. (2012). Global warming in schools: An inquiry about the competing conceptions of high school social studies and science curricula and teachers (Yayımlanmamıs Doktora Tezi). University of WisconsinMadison. Wisconsin.

Meehan, C. R., Levy, B. L. \& Collet-Gildard, L. (2016). Global climate change in U.S. high school curricula: Portrayals of the causes, consequences, and potential responses. Science Education, 102, 498-528.

Nema, P., Nema, S. \& Roy, P. (2012). An overview of global climate changing in current scenario and mitigation action. Renewable and Sustainable Energy Reviews, 16, 2329- 2335.

Njoku, C. (2016). Awareness of climate change and sustainable development issues among junior secondary school (JSS) students in Port Harcourt Metropolis, Nigeria. International Journal of Curriculum and Instruction, $8(2), 29-40$.

Özdem, Y., Dal, B., Öztürk, N., Sönmez, D. \& Alper, U. (2014). What is that thing called climate change by seventh-grade student. International Research in Geographical and Environmental Education, 23(4), 294313.

Özkaral, T. C. (2019). Küresel ısınma ve iklim değişikliği konusunun Türkiye, Kanada (Ontario) ve Hong Kong sosyal bilgiler öğretim programlarında karşılaştırmalı olarak incelenmesi. International Journal of Education Technology and Scientific Researches, 4(8), 1-14.

Öztürk, C. (2012). Sosyal bilgiler: Kavram, içerik ve programı. C. Öztürk (Ed.). Sosyal bilgiler öğretimi: Demokratik vatandaşlık eğitimi içinde (ss. 2-30). Ankara: Pegem Akademi.

Öztürk, K. (2002). Küresel iklim değişikliği ve Türkiye’ye olası etkileri. Gazi Eğitim Fakültesi Dergisi, 22(1), $47-$ 65.

SBDÖP (2018). Sosyal Bilgiler Dersi Öğretim Programı $18.04 .2021 \quad$ tarihinde https://mufredat.meb.gov.tr/Dosyalar/201812103847686SOSYAL\%20B\%C4\%BOLG\%C4\%BOLER\%20\%C3\%96\%C4\%9ERET\%C4\%BOM\%20PROGRAMI\%20.p $\underline{d f}$ adresinden edinilmiştir.

Siegner, A. \& Stapert, N. (2020). Climate change education in the humanities classroom: a case study of the Lowell school curriculum pilot. Environmental Education Research, 26(4), 511-531.

Stevenson, R. B., Nicholls, J. \& Whitehouse, H. (2017). What is climate change education? Curriculum Perspectives, 37(67), 67-71.

Tuncel, G. (2017). Sosyal bilgiler dersinde karikatürlerle küresel 1sınma eğitimi üzerine örnek bir çalışma. Marmara Coğrafya Dergisi, 35, 87-94.

Ulutaş, B. (2015). Doküman incelemesi. F. N. Seggie ve Y. Bayyurt (Ed.), Nitel araştırma: Yöntem, teknik, analiz ve yaklaşımları içinde (ss. 279-297). Ankara: Anı Yayıncılık.

UNICEF (2009). Climate change, children and youth: Local connections to global issues. https://www.unicef.ca/sites/default/files/legacy/imce_uploads/Docs/policy/health.pdf adresinden 18.04.2021 tarihinde edinilmiştir.

Ürey, M., Çolak, K., Bozdemir Yüzbaşığlu, H. \& Kaymakçı, S. (2020). Comparison of prospective science and social studies teachers' knowledge levels of and misconseptions about atmospheric environmental problems. International Electronic Journal of Environmental Education, 10(2), 216-236.

Wang, Y.S. \& Gu, J. D. (2021). Ecological responses, adaptation and mechanism of mangrove wetland ecosystem to global climate change and antropogenic activities. International Biodeterioration \& Biodegradation, 162, $1-14$. 
Wilbanks, T. J. \& Sathaye, J. (2007). Integration mitigation and adaptation as responses to climate change: a synthesis. Mitigation and Adaptation Strategies for Global Change, 12(5), 957-962.

Yıldırım, A. \& Şimşek, H. (2013). Sosyal bilimlerde nitel araştırma yöntemleri. Ankara: Seçkin Yayıncılık. 


\section{EXTENDED ABSTRACT}

The effects of Global Climate Change (GCC) on natural life has been felt since the last years of the $20^{\text {th }}$ century. Ice thickness has begun to thin and permanent snow lines have begun to shrink especially in the polar regions. In addition, potable water resources have begun to run out, faunas and floras have begun to change and many species have become endangered. Furthermore, it is observed that the seasons of harvesting plants have begun to change and the quality of agricultural products have been getting worse in many regions in the world. Besides, some extreme weather events that have not occurred at all have begun to appear, sea levels and forest fires have begun to increase in some regions. These "natural disasters" started to affect human life in many ways (IPCC, 2014). According to some projections, due to the ecological problems caused by GCC on the natural life, some economic problems such as the deterioration in the agricultural production balance, problems in transportation services; some psychological problems such as hopelessness, depression, anxiety disorders, stress, lack of belonging, substance addiction and some social problems such as immigration, class struggles, unemployment and water wars will be experienced soon (Brady, 2020; Clayton, 2015). Besides all these, it is expected that some infectious diseases will be seen more frequently due to increasing temperatures (McMichaels and Haines, 1997). The individuals who will be affected most by these problems will be today's children and youth living especially in underdeveloped and developing countries (UNICEF, 2009; Bongay and Blum, 2010).

It can be said that the social studies course is one of the most appropriate courses by which students can gain positive behaviors and awareness about the expected social and economic impacts of GCC (Harris et al., 2016; Kissling and Bell, 2020, Kumler and Vosburg-Blueam, 2014). Because the social studies course, which has an interdisciplinary structure, provides students with the knowledge, skills and value that will enable them to take an active role in social life, and helps them develop an awareness of social problems and behavior towards solving these problems (Öztürk, 2012; SBDÖP, 2018).

Social studies including topics about GCC is taught in $4^{\text {th }}$ grades in primary schools, $5^{\text {th }}, 6^{\text {th }}$ and $7^{\text {th }}$ grades in middle schools (Özdem et al., 2017). When the social studies course objective is examined, it is seen that some cognitive characteristics and affective behaviours such as sensitivity towards natural life, awareness about limited resources, protection of the environment, sustainable life, social problems, civic participation are aimed. In addition, the $4^{\text {th }}$ learning outcome of Global Connections learning domain in the $7^{\text {th }}$ grade curriculum is directly related to GCC (SBDÖP, 2018).

When literature was examined, it was seen that some research was conducted about GCC and social studies education (Aksan ve Çelikler, 2013; Chandler ve Marri, 2012; Dal et al., 2015; Damico ve Panos, 2018; Karakuş ve Yel, 2019; Kaya, 2013; Kissling ve Bell, 2020; Meehan, 2012; Meehan, Levy ve Collet-Gildard, 2016; Njoku, 2016; Özkaral, 2019; Tuncel, 2017; Ürey et al., 2020). However, limited research was conducted about the place of GCC in the social studies textbooks in the literature (Demir, 2018). Based on the importance of GCC in social studies education and literature gap, it aims to examine information about GCC in middle school social studies textbooks which are used in the 2020-2021 academic year in Turkey.

Document analysis was employed in this study. $5^{\text {th }}, 6^{\text {th }}$ and $7^{\text {th }}$-grade social studies textbooks were examined according to the purpose of the study. Descriptive analysis was conducted to analyze documents. External audit and peer debriefing strategies were used for trustworthiness of the study. 
It is concluded that most of the information about GCC is presented in the $7^{\text {th }}$-grade social studies textbook. Besides, only global warming which is the main reason for GCC is placed in the $5^{\text {th }}$-grade social studies textbook. It is also seen that information about global warming is quite limited. On the other hand, it was determined that no information related to GCC were presented in the $6^{\text {th }}$-grade social studies textbook.

It was found that quite limited information was stated about how GCC occurs, reasons and expected effects of GCC in social studies textbooks. It was stated that GCC change is caused only by the excessive emission of greenhouse gases, and GCC was not associated with unconscious consumerism and unconscious use of forests. In addition, it was determined that this information is not supported or explain through various images.

Drought, migration, natural disasters, increase in sea and ocean water levels and melting of glaciers are among the direct effects of GCC are shown, but information on the psychological, political and economic problems that will be caused by GCC are not included in social studies textbooks. In addition, it was revealed that the statements about the effects of the GCC which will be felt more soon are not explained effectively.

In addition, it was found that various assessment and evaluation tools were not used in social studies textbooks. It was also found that the evaluations about GCC in the social studies textbook were not related to the metacognitive domains of the students.

Based on the results of the study, the followings could be suggested.

- Information about GCC should be stated at every stage of middle school by the spiral structure of the social studies curriculum.

- Effective images could be included to explain especially reasons and expected effects of GCC.

- GCC could be associated with issues related to climate, population, settlement and economic activities, especially in the scope of People, Places and Environments Learning Domain at different grade levels. 